\title{
SERUM LUTEINIZING HORMONE AND FOLLICLE STIMULATING HORMONE IN NORMAL CHILDREN AND PATIENTS WITH VARIOUS CLINICAL DISORDERS
}

\author{
PETER A. LEE \\ Department of Pediatrics and The Reproductive Endocrinology Program, \\ Departments of Pathology and Obstetrics and Gynecology, \\ University of Michigan Medical Center, Ann Arbor, Michigan, U.S.A.
}

\begin{abstract}
SUMMARY
Serum concentrations of luteinizing hormone (LH) and follicle stimulating hormone (FSH) were determined in 329 normal children and 185 individuals with endocrinological abnormalities or variations of development. A significant increase of gonadotrophins is noted at the onset of puberty among the boys and at menarche for girls. The values are compared with serum concentrations of LH and FSH in children with abnormalities of sexual development, pituitary malfunction as well as other clinical abnormalities. Comparable levels for age and stage of development were found for premature thelarche, premature adrenarche, cryptorchidism, male pseudohermaphroditism and pubertal gynaecomastia. Hypogonadal individuals (Klinefelter's and Turner's syndrome, pure ovarian dysgenesis and testicular dysgenesis) have markedly elevated values while those with pituitary hypofunction had low values. Patients with sexual prococity tended to have elevated concentrations.
\end{abstract}

Several laboratories have reported circulating levels of pituitary gonadotrophins in children of various ages. These determinations were made possible by the development of sensitive radioimmunoassays capable of measuring plasma levels of pituitary gonadotrophins in states in which low levels exist. Analysis of changes of levels at various stages of sexual development have been reported for each sex for LH (Johanson et al., 1969; Yen et al., 1969; Burr et al., 1970; Lee et al., 1970; Root et al., 1970; Sizonenko et al., 1970; Jenner et al., 1972; Winter \& Faiman, 1972) and FSH (Raiti et al., 1969; Burr et al., 1970; Lee et al., 1970; Yen \& Vicic, 1970; Winter \& Faiman, 1972). Several investigators have reported serum gonadotrophins in abnormal states of sexual development (Kenny et al., 1969; Guyda et al., 1969; Root et al., 1970; Penny et al., 1970; Jenner et al., 1972). Such determinations may facilitate the diagnosis of some disease states.

In the present study, serum LH and FSH in 185 patients suffering from a variety of clinical disorders including hypogonadism, aberrances of sexual development and other

Correspondence: Dr Peter A. Lee, 3-110 Children's Medical and Surgical Center, Johns Hopkins Hospital, 601 North Broadway, Baltimore, Maryland 21205, U.S.A. 
endocrinopathies are reported. For comparison a group of normal subjects at various ages and stages of sexual development from birth to age 20 are included. Among the normal group, special attention was directed to the first 2 years of life for both sexes.

\section{MATERIALS AND METHODS}

Except where noted, peripheral venous blood was obtained from patients before any treatment. Venous samples from neonates were obtained from the umbilical cord. The blood was allowed to clot, refrigerated and centrifuged. Serum was drawn off and stored at $-20^{\circ} \mathrm{F}$ for periods up to a month. The double antibody radioimmunoassay procedures employed for $\mathrm{LH}$ and FSH, the assay variability and sensitivities have been described elsewhere (Lee et al., 1970). The Second International Reference Preparation-Human Menopausal Gonadotrophin was used as a standard. There is no cross-reactivity with either assay for TSH. Two hypothyroid patients, aged 8 and 12, have been reported to have very high TSH levels and appropriate levels of LH and FSH (Midgley \& Reichert, 1969). The same study reported that the material being measured in the FSH radioimmunoassay had an electrophoretic mobility different from bioassayable TSH. All samples were assayed in duplicate.

Staging of sexual development was based on genital size and pubic hair growth for boys and breast development and pubic hair for girls according to Tanner's (1962) staging. Normal individuals reported herein include those previously reported (Lee et al., 1970). The Student $t$ test was used for comparisons within sexes between adjacent ages/stages and to compare stages of normal boys and those with constitutional delay.

Patients included in this study were carefully studied for confirmation of diagnosis. The children with premature thelarche, premature adrenarche and precocious puberty were all seen at follow-up visits. Differentiation between constitutional delay of puberty and hypogonadotrophic hypogonadism was not made until the patients attained an age of 18 years without pubertal changes or until they were followed from 2 to 3 years. Serum collections were begun in 1967 and continued until 1971 and hence all diagnoses for boys younger than 17 were made retrospectively. Delayed puberty among the girls was diagnosed when no sexual development was present until after the 14th year or no menses until after the 16th year associated with delayed bone age. All patients with Klinefelter's syndrome had an XXY karyotype. The diagnosis of ovarian dysgenesis was based on normal Barr bodies, XX karyotype, elevated urinary gonadotrophins by bioassay and, in two instances, by ovarian biopsy. Turner's syndrome or mosaic Turner's were diagnosed by chromosomal studies. Three of the patients with a mosaic pattern had XO/XX patterns and one had $\mathrm{X}$ /isochrome $\mathrm{X}$.

\section{RESULTS}

Table 1 indicates normal LH and FSH values for various ages and stages of sexual development and is included as a reference for comparison with levels of those in patients with abnormal clinical states. The mean LH and FSH levels with 1 SD for boys from Stages I to IV are plotted in the shaded areas in Fig. 1. Levels are similarly depicted for men and for women during the mid-follicular phase of the menstrual cycle in the shaded areas in Fig. 2. A gradual increase of both LH and FSH was present in boys from age 2 to 20 . Significant increase occurred only when Stage I (prepubertal, age 7-8) was compared with 
TABLE 1. Serum gonadotrophin levels in normal individuals at various ages and stages

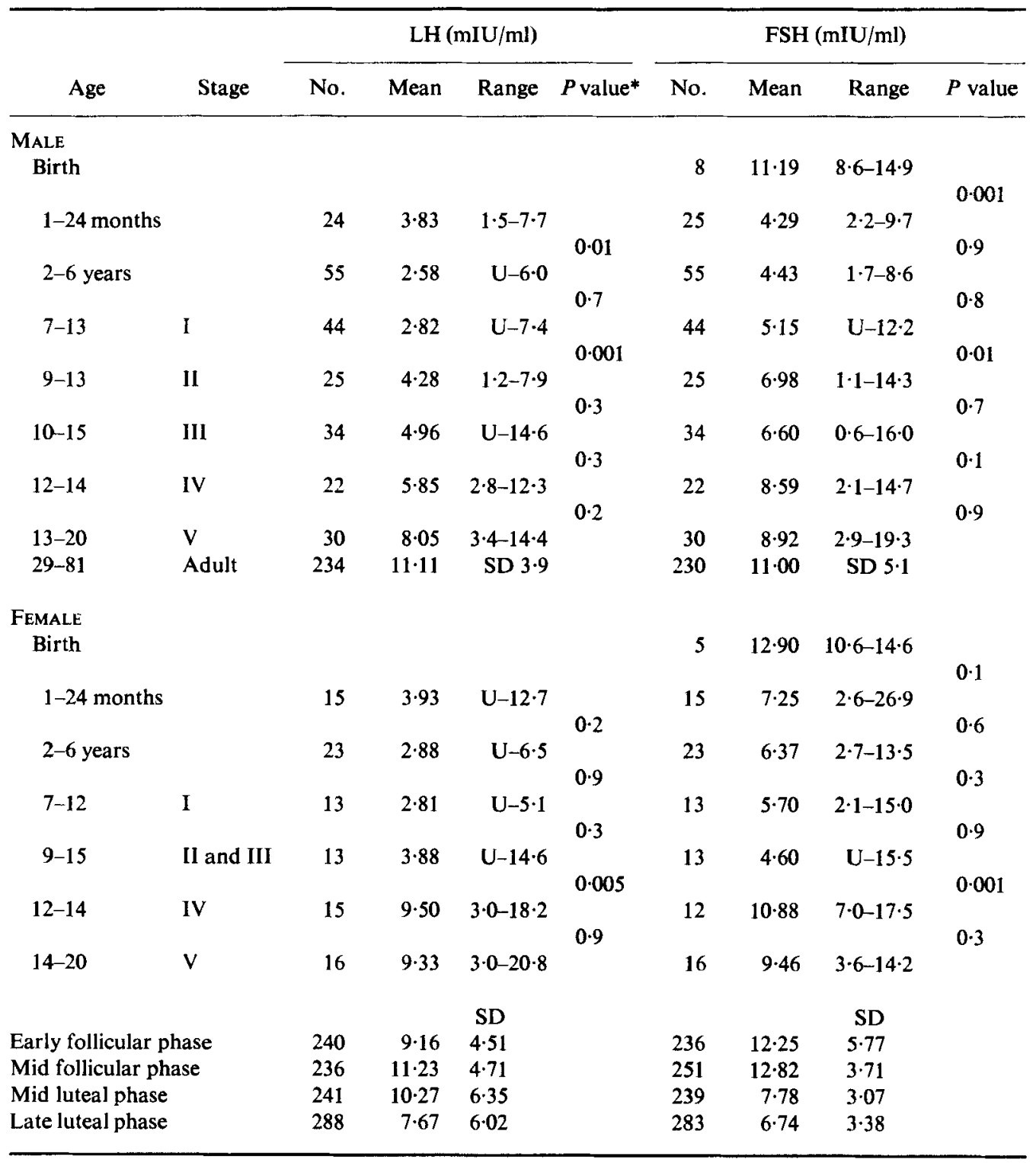

* $P$ values: significance limit indicated by the Student $t$ test when adjacent groups analysed.

Stage II (initial changes of puberty) for both LH and FSH. A marked increase of LH and FSH occurred at menarche in girls. This was the only point of significant increase among the girls.

LH concentrations did not differ significantly when comparison of levels between prepubertal boys and girls at various ages was done. Concentrations of FSH, however, were significantly higher in girls from 1 to 24 months $(P>0.05)$ and 2-6 years $(P>0.001)$ than boys of comparable ages. 


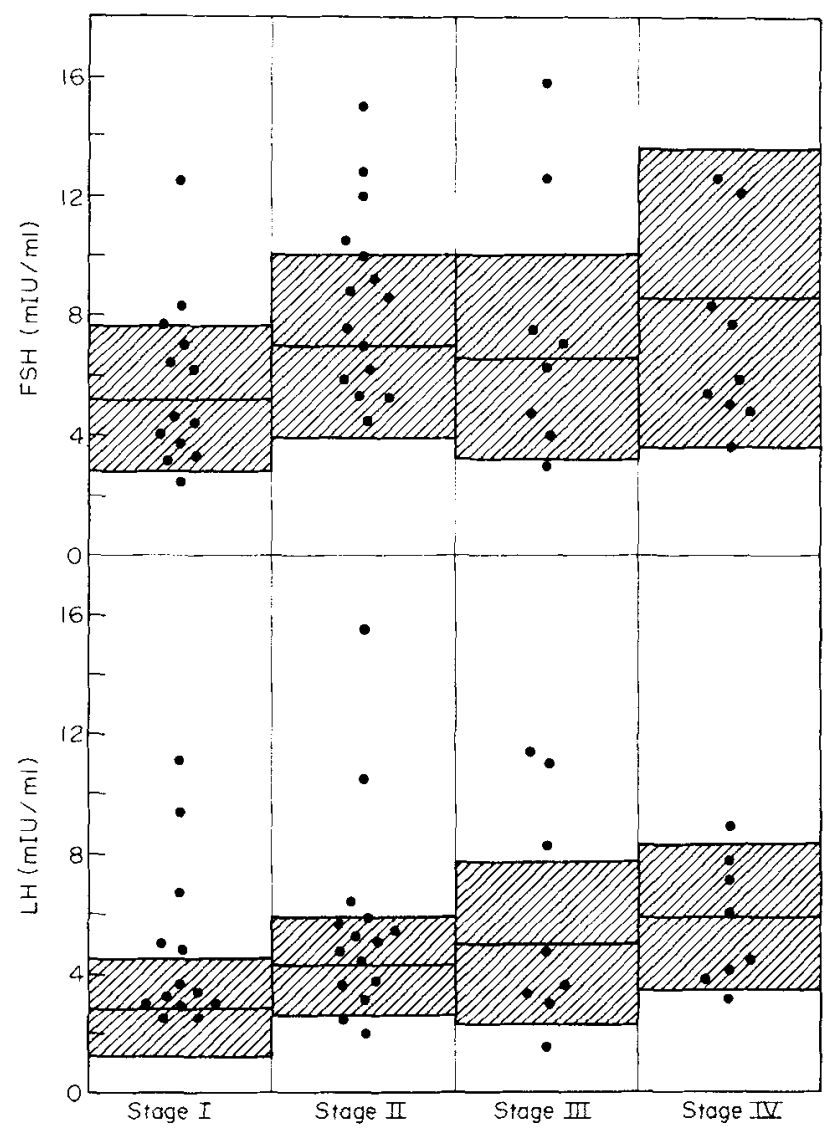

FIG. 1. Serum concentrations of LH and FSH in boys with constitutional delay of growth and development plotted according to stage of sexual development. Mean LH and FSH levels $( \pm 1 \mathrm{SD})$ for normal boys are shown in the shaded areas.

Tables 2, 3 and 4 include gonadotrophin levels for various disease states. When Table 2 (abnormalities of sexual development) is used to compare means and ranges of gonadotrophins in these patients with age and/or stage of normal children, comparable levels of LH and FSH are present for premature adrenarche, cryptorchidism, male pseudohermaphroditism, pubertal gynaecomastia and premature thelarche. One exception is noted among those with premature thelarche. Girls and boys with precocious puberty tended to have elevated gonadotrophins for age but normal levels for stage. Although LH is significantly higher $(P<0.0025)$ for Stage I in boys with constitutional delay than normal boys, there was no other statistical difference when LH and FSH were compared for comparable stages in boys with normal development and constitutional delay (Fig. 1). The ranges for the early stages of sexual development, however, reach a higher level.

Males and females with hypogonadism (Fig. 2) had markedly elevated LH and FSH levels with the exception of one girl with a mosaic XO/XX karyotype and few stigmata of Turner's syndrome who was developing sexually but had not menstruated. Among patients with pituitary malfunction (Table 3) those with hypogonadotrophic hypogonadism, 


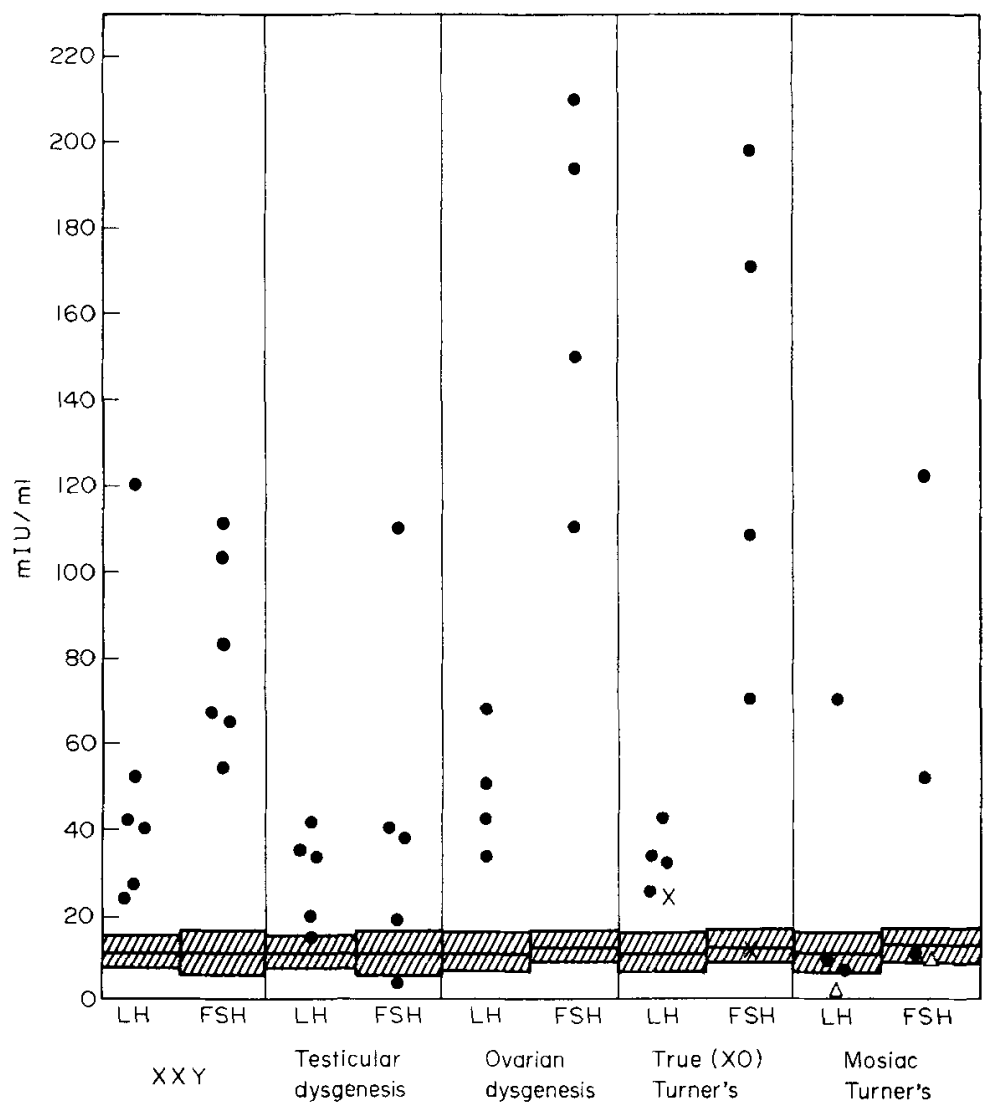

FIG. 2. Serum concentrations of LH and FSH in hypogonadal individuals. Mean \pm 1 SD is included for men and women during the mid-follicular phase of the menstrual cycle. $\times$, Oestrogen-treated Turner's; $\triangle$, mosaic Turner's with sexual development.

idiopathic panhypopituitarism, growth hormone deficiency with hypogonadism, postsurgical craniopharyngioma and chromophobe adenoma had LH and FSH values comparable with prepubertal individuals. None of the patients with post-surgical craniopharyngiomas had sexual development. Those with growth hormone deficiency without hypogonadism had values comparable to normals for age and stage. The men with acromegaly had normal adult genitalia and normal adult levels of gonadotrophins.

The three prepubertal girls with treated congenital virilizing adrenal hyperplasia had normal gonadotrophin levels for age and stage (Table 4). The LH value in one of the untreated women with congenital virilizing adrenal hyperplasia was elevated. Both of these women had been previously treated and had menstruated but apparently were not taking their medication regularly and were amenorrhoeic at the time of sampling. However, the man and both the cycling and non-cycling women with acquired hypothyroidism had elevated LH values; the non-cycling woman who had Hashimoto's thyroiditis also had postmenopausal FSH values. The LH values for the patient with hyperparathyroidism appears elevated but may not be so as this girl was having regular menstrual cycles and may have been at mid-cycle or in mid-luteal phase when sampled. 
TABLE 2. Serum gonadotrophin levels in variations of sexual development

\begin{tabular}{|c|c|c|c|c|c|c|c|c|}
\hline & \multirow{2}{*}{ Sex } & \multirow{2}{*}{$\begin{array}{c}\text { Age } \\
\text { (years) }\end{array}$} & \multicolumn{3}{|c|}{$\mathrm{LH}(\mathrm{mIU} / \mathrm{ml})$} & \multicolumn{3}{|c|}{ FSH (mIU/ml) } \\
\hline & & & No. & Mean & Range & No. & Mean & Range \\
\hline Premature thelarche & F & $1-7$ & 2 & - & $2 \cdot 3-7 \cdot 6$ & 2 & - & $8 \cdot 7-12 \cdot 7$ \\
\hline Premature adrenarche & F & 7 & 1 & $3 \cdot 1$ & - & 3 & $7 \cdot 8$ & $4 \cdot 6-12 \cdot 9$ \\
\hline $\begin{array}{l}\text { Precocious puberty } \\
\text { Premenarche } \\
\text { Postmenarche } \\
\text { CNS tumours }\end{array}$ & $\begin{array}{l}\mathbf{F} \\
\mathbf{F} \\
\mathbf{M}\end{array}$ & $\begin{array}{r}4-7 \\
13-9 \\
2-7\end{array}$ & $\begin{array}{l}3 \\
4 \\
1\end{array}$ & $\begin{array}{l}4 \cdot 8 \\
2 \cdot 8 \\
4 \cdot 4\end{array}$ & $\begin{array}{c}2 \cdot 1-9.8 \\
<1 \cdot 0-3.5 \\
-\end{array}$ & $\begin{array}{l}3 \\
4 \\
2\end{array}$ & $\begin{array}{l}9 \cdot 4 \\
6 \cdot 7\end{array}$ & $\begin{array}{l}8 \cdot 3-10 \cdot 3 \\
2 \cdot 6-10 \cdot 4 \\
4 \cdot 9-12 \cdot 9\end{array}$ \\
\hline $\begin{array}{l}\text { Constitutional delay } \\
\text { Premenarche }\end{array}$ & $\mathbf{F}$ & $14-17$ & 9 & $7 \cdot 6$ & $<1.5-19.6$ & 9 & $14 \cdot 2$ & $1 \cdot 5-24 \cdot 6$ \\
\hline $\begin{array}{l}\text { Cryptorchidism } \\
\text { Prepubertal } \\
\text { Unilateral } \\
\text { Bilateral } \\
\text { Pubertal-repaired }\end{array}$ & & $\begin{array}{l}8 \frac{1}{2}-12 \\
14-18 \\
16-18\end{array}$ & $\begin{array}{l}4 \\
3 \\
2\end{array}$ & $\begin{array}{l}4 \cdot 4 \\
4 \cdot 3 \\
-\end{array}$ & $\begin{array}{c}3 \cdot 2-5 \cdot 6 \\
<2 \cdot 0-7 \cdot 7 \\
7 \cdot 7-11 \cdot 4\end{array}$ & $\begin{array}{l}4 \\
3 \\
2\end{array}$ & $\begin{array}{c}7.4 \\
5.9 \\
-\end{array}$ & $\begin{array}{c}<1 \cdot 5-10 \cdot 7 \\
4 \cdot 5-8 \cdot 3 \\
4 \cdot 9-15 \cdot 8\end{array}$ \\
\hline $\begin{array}{l}\text { Pseudohermaphrodites, male, } \\
\text { idiopathic }\end{array}$ & & $1 \frac{1}{4}-10$ & 3 & $2 \cdot 9$ & $<1.0-6.4$ & 3 & $5 \cdot 8$ & $2 \cdot 6-11 \cdot 5$ \\
\hline Pubertal gynaecomastia & $\mathbf{M}$ & $15-21$ & 6 & $4 \cdot 5$ & $3 \cdot 4-8 \cdot 2$ & 6 & 7.5 & $<1.5-15.0$ \\
\hline
\end{tabular}

TABLE 3. Serum gonadotrophin levels in various types of pituitary malfunction

\begin{tabular}{|c|c|c|c|c|c|c|c|}
\hline & \multirow{2}{*}{ Sex } & \multirow{2}{*}{ No. } & \multirow{2}{*}{$\begin{array}{c}\text { Age } \\
\text { (years) }\end{array}$} & \multicolumn{2}{|c|}{ LH (mIU/ml) } & \multicolumn{2}{|c|}{$\mathrm{FSH}(\mathrm{mIU} / \mathrm{ml})$} \\
\hline & & & & Mean & Range & Mean & Range \\
\hline Hypogonadotrophic hypogonadism & $\mathbf{M}$ & 19 & $14-22$ & 3.9 & $<1 \cdot 5-5 \cdot 7$ & $4 \cdot 3$ & $<1.5-6.8$ \\
\hline Panhypopituitarism, idiopathic & $\begin{array}{l}\text { M } \\
\text { F }\end{array}$ & $\begin{array}{l}4 \\
2\end{array}$ & $\begin{array}{c}16-40 \\
15\end{array}$ & $\begin{array}{l}3.6 \\
-\end{array}$ & $\begin{array}{l}<2.0-4.8 \\
<1.5-3.4\end{array}$ & $\begin{array}{l}4 \cdot 5 \\
-\end{array}$ & $\begin{array}{r}<2 \cdot 4-7 \cdot 5 \\
6 \cdot 0-6 \cdot 5\end{array}$ \\
\hline $\begin{array}{l}\text { Growth hormone deficiency } \\
\text { With hypogonadism } \\
\text { Without hypogonadism }\end{array}$ & $\begin{array}{l}\mathbf{M} \\
\mathbf{M}\end{array}$ & $\begin{array}{l}1 \\
3\end{array}$ & $\begin{array}{c}15 \\
14-17\end{array}$ & $\begin{array}{l}3.7 \\
5.0\end{array}$ & $<2 \cdot 0-7 \cdot 4$ & $\begin{array}{l}4 \cdot 2 \\
7 \cdot 3\end{array}$ & $4 \cdot 2-10 \cdot 1$ \\
\hline $\begin{array}{l}\text { Organic hypopituitarism } \\
\text { Craniopharyngioma postsurgical } \\
\text { Cryohypophysectomy for diabetes } \\
\text { mellitus } \\
\text { Hypophysectomy for acromegaly } \\
\text { Chromophobe adenoma }\end{array}$ & $\begin{array}{c}M / F \\
F \\
M \\
M\end{array}$ & $\begin{array}{l}5 \\
1 \\
1 \\
1\end{array}$ & $\begin{array}{l}22 \\
37 \\
19\end{array}$ & $\overline{-}$ & $\begin{array}{l}9 \cdot 1 \\
2 \cdot 4 \\
2 \cdot 8\end{array}$ & $\begin{array}{l}- \\
- \\
-\end{array}$ & $\begin{array}{l}3 \cdot 5 \\
2 \cdot 9 \\
3 \cdot 4\end{array}$ \\
\hline Acromegaly & $\mathbf{M}$ & 2 & $24-36$ & - & $9 \cdot 1-9 \cdot 3$ & - & $10 \cdot 2-18 \cdot 3$ \\
\hline
\end{tabular}


TABLE 4. Serum gonadotrophin levels in various clinical conditions

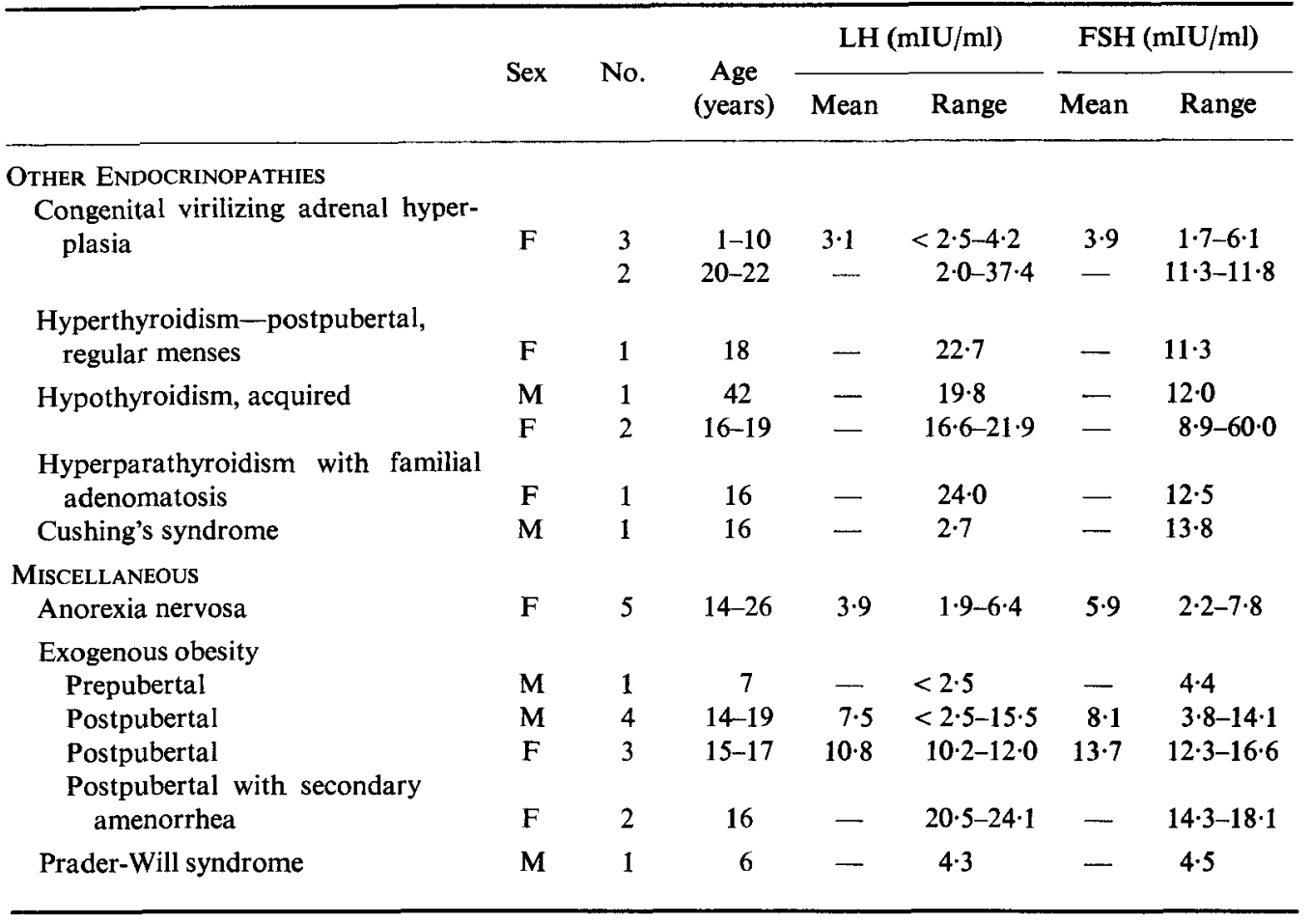

Gonadotrophins were apparently normal in exogenous obesity. Patients with anorexia nervosa had low levels, comparable with prepubertal girls. All of these patients were amenorrhoeic and were beyond the stage of acute weight loss. The 6-year-old boy with PraderWilli syndrome had levels well within the prepubertal range.

\section{DISCUSSION}

The data from normal prepubertal and pubertal children, expanded from our earlier report (Lee et al., 1970), show a significant increase of gonadotrophins in boys at the onset of puberty. After infancy, there was a gradual increase of levels of both hormones among boys but not girls. Except during the first 2 years of life, neither girls nor boys of prepubertal ages showed significantly different levels. However, as pointed out by Faiman \& Winter (1971), and in a previous report from this laboratory (Lee et al., 1970), FSH appears to be higher in girls than boys during the first 6 years of life. This, however, was not true for cord blood samples. Our data also indicate that LH is possibly higher $(P<0.05)$ in girls than boys from birth to 6 years depending upon grouping of data. Cord blood levels of FSH from male infants were higher than levels in boys 1-24 months of age. This was not true for girls. Also LH concentrations in boys during the first 2 years was higher than in those 2-6 years of age. These data suggest a functional difference during infancy in the role played by the testes and ovary in hypothalamic-pituitary regulation. The hypothalamus may become more sensitive to the feedback substances produced by the gonad or the gonad 
may produce a greater amount. $\mathrm{LH}$ in cord blood samples could not be measured because of cross reaction with HCG (Midgley et al., 1967).

Our data on patients with constitutional delay indicate that these patients have similar levels at comparable stages of development as normal boys. Some levels are low for age when compared with the average child, as previously reported (Guyda et al., 1969; Root et al., 1970; Penny et al., 1970) making difficult the differentiation of constitutional delay in growth and development from isolated gonadotrophin deficiency. Also, as previously reported (Guyda et al., 1969), once mid-puberty is reached the age difference is not present.

Patients with premature pubarche and pubertal gynaecomastia had gonadotrophin concentrations similar to others of comparable ages, as recorded by others (Guyda et al., 1969; Root et al., 1970; Penny et al., 1970). This indicates that these conditions are not due to excessive gonadotrophin release and also that gonadotrophins are not excessively suppressed by the steroids which may be causing the precocity. Our data and those of Root et al. (1970) show that male pseudohermaphrodites with some masculinization have a normal interactive feedback mechanism, while those with testicular feminization apparently do not (Tremblay et al., 1972).

One of our two patients with premature thelarche had an elevated concentration of $\mathrm{LH}$. This is consistent with the slight increase noted by Kenny et al. (1969) and the elevated levels of LH seen in two of fifteen patients reported by Root et al. (1970). However, Penny et al. (1970) and Guyda et al. (1969) did not note any such patients with elevated levels. These data may suggest that there is an early, perhaps sporadic, LH release operative in early thelarche. Our data, those of Root et al. (1970) and Penny et al. (1970) indicate that gonadotrophins are not constantly elevated in idiopathic sexual precocity or precocity due to CNS pathology. Hence, while these patients are likely to have increased gonadotrophin secretion rates, single sample estimations are inadequate to make the diagnosis.

Patients with Turner's phenotype do not necessarily have complete gonadal agenesis since gonadotrophins are not uniformly elevated. However, those Turner's in this report with an XO karyotype apparently have no functional ovarian tissue and consequently elevated gonadotrophins. Conversely, those with a mosaic karyotype in leucocytes without the full phenotypic appearance of classic Turner's syndrome may have functional ovaries. The youngest patients in our study were 13 years old; others have reported markedly elevated gonadotrophins at a much younger age (Guyda et al., 1969; Root et al., 1970; Jenner et al., 1972) with FSH rising before LH.

All of our patients with Klinefelter's syndrome had markedly elevated gonadotrophins while those with other types of testicular dysgenesis did not. The difference between the serum concentrations in our patients and the lower values reported by others (Saxena et al., 1968) in Klinefelter's syndrome may be a reflection of the differences in gonadal function among individuals with this condition (Paulsen et al., 1968).

The elevated levels of gonadotrophins present in patients with hypothyroidism are of interest since sexual precocity is known to occur among these patients. Increased synthesis of TSH may be related to increased gonadotrophin synthesis since TSH and the gonadotrophins may have the same alpha subunit (Pierce et al., 1971; Rathnam \& Saxena, 1971).

It is recognized that the value of a single random plasma LH or FSH value is limited in assessing clinical states because serum gonadotropin levels fluctuate rapidly. Nevertheless, there would appear to be several clinical situations in which our data indicate that gonadotrophin levels may be a useful clinical tool. They include (a) differentiation of hypogona- 
dotrophic hypogonadism from hypergonadotrophic (including XO, but not necessarily phenotypic Turner's syndrome), (b) determination of the presence of a functional gonad in pseudohermaphroditism, (c) provision of evidence for anorexia nervosa. However, a single gonadotrophin determination may not differentiate between sexual precocity and premature thelarche.

\section{ACKNOWLEDGMENTS}

Appreciation is expressed to Dr A. Rees Midgley, Jr, Dr Robert B. Jaffe and Mrs Mary Westervelt for their help. This work was supported in part by grants from the USPHS (NIH-HD-02929), The Population Council and The University of Michigan Cancer Research Institute.

\section{REFERENCES}

BUrR, I.M., Sizonenko, P.C., Kaplan, S.L. \& Grumbach, M.M. (1970) Hormonal changes in puberty. I. Correlation of serum luteinizing hormone and follicle stimulating hormone with stages of puberty, testicular size, and bone age in normal boys. Pediatric Research, 4, 25 .

FAIMAN, C. \& WinTER, J.S.D. (1971) Sex differences in gonadotropin concentrations in infancy. Nature, $232,130$.

Guyda, H.J., Johanson, A.J., Migeon, C.J. \& Blizzard, R.M. (1969) Determination of serum luteinizing hormone (SLH) by radioimmunoassay in disorders of adolescent sexual development. Pediatric Research, 3, 538.

JenNer, M.R., Kelch, R.P., Kaplan, S.L. \& Grumbach, M.M. (1972) Hormonal changes in puberty. IV. Plasma estradiol, LH and FSH in prepubertal children, pubertal females, and in precocious puberty, premature thelarche, hypogonadism, and in a child with a feminizing ovarian tumor. Journal of Clinical Endocrinology and Metabolism, 34, 521.

Johanson, A.J., Guyda, H.J., Light, C., Migeon, C.J. \& Blizzard, R.M. (1969) Serum luteinizing hormone by radioimmunoassay in normal children. Journal of Pediatrics, 74, 416.

Kenny, F.M., Midgley, A.R., JR, Jaffe, R.B., Garces, L.Y., Vazquez, A. \& Taylor, F.H. (1969) Radioimmunoassayable serum LH and FSH in girls with sexual precocity, premature thelarche and adrenarche. Journal of Clinical Endocrinology and Metabolism, 29, 1272.

LeE, P.A., MidGLEY, A.R., JR \& JAFFE, R.B. (1970) Regulation of human gonadotropins. VI. Serum follicle stimulating and luteinizing hormone determinations in children. Journal of Clinical Endocrinology and Metabolism, 31, 248.

Midgley, A.R., JR \& Reichert, L.E. (1969) Specificity studies on a radioimmunoassay for human follicle stimulating hormone. Protein and Polypeptide Hormones (Ed. Margoulies), p. 117. Excerpta Medica Foundation, Amsterdam.

Midgley, A.R., JR, FoNG, I.F. \& JAFFe, R.B. (1967) Gel filtration radioimmunoassay to distinguish human chorionic gonadotropin from luteinizing hormone. Nature, 213, 733.

Paulsen, C.A., Gordon, D.L., Carpenter, R.W., Gandy, H.M. \& Drucker, W.D. (1968) Klinefelter's syndrome and its variants: A hormonal and chromosomal study. Recent Progress in Hormone Research, $24,321$.

Penny, R., Guyda, H.J., Baghdassarian, A., Johanson, A.J. \& Blizzard, R.M. (1970) Correlation of serum follicular stimulating hormone (FSH) and luteinizing hormone (LH) as measured by radioimmunoassay in disorders of sexual development. Journal of Clinical Investigation, 49, 1847.

Pifrce, J.G., Bahl, O.P., Cornell, J.S. \& Swaminathan, N. (1971) Biologically active hormones prepared by recombination of the alpha chain of human chorionic gonadotropin and the hormone specific chain of bovine thyrotropin or of bovine luteinizing hormone. Journal of Biological Chemistry, 246, 2321.

Ratti, S., Johanson, A.J., Light, C., Migeon, C.J. \& Blizzard, R.M. (1969) Measurement of immunologically reactive follicle stimulating hormone in serum of normal male children and adults. Metabolism, 18, 234.

RATHNAM, P. \& SAXENA, B.B. (1971) Subunits of luteinizing hormone from human pituitary glands. Journal of Biological Chemistry, 246, 7087. 
Root, A.W., Moshang, T., JR, Bongiovanni, A.M. \& Eberlern, W.R. (1970) Concentrations of plasma luteinizing hormone in infants, children and adolescents with normal and abnormal gonadal functions. Pediatric Research, 4, 175.

Saxena, B.B., Demura, H., Gandy, H.M. \& Peterson, R.E. (1968) Radioimmunoassay of human follicle stimulating and luteinizing hormones in plasma. Journal of Clinical Endocrinology and Metabolism, 28, 519.

Sizonenko, P.C., Burr, I.M., Kaplan, S.L. \& Grumbach, M.M. (1970) Hormonal changes in puberty. II. Correlation of serum luteinizing hormone with stages of puberty and bone age in girls. Pediatric Research, 4, 36.

TANner, J.M. (1962) Growth at Adolescence, 2nd edn. Blackwell Scientific Publications, Oxford.

Tremblay, R.R., Foley, T.P., Jr, Corvol, P., Park, I.J., Kowarski, A., Blizzard, R.M., Jones, H.W., JR \& Migeon, C.J. (1972) Plasma concentrations of testosterone, dihydrotestosterone, testosteroneoestradiol binding globulin and pituitary gonadotropins in the syndrome of male pseudohermaphroditism with testicular feminization. Acta Endocrinologica, 70, 331.

Winter, J.S.D. \& Faiman, C. (1972) Pituitary-gonadal relations in male children and adolescents. Pediatric Research, 6, 126.

Yen, S.S.C. \& ViCIC, W.J. (1970) Serum follicle stimulating hormone levels in puberty. American Journal of Obstetrics and Gynecology, 106, 134.

Yen, S.S.C., VICIC, W.J. \& KeARChNeR, D.V. (1969) Gonadotropin levels in puberty. I. Serum luteinizing hormone. Journal of Clinical Endocrinology and Metabolism, 29, 382. 